\title{
Genetic Dissection of Wheat Genotypes Using Morpho-Physiological Traits for Terminal Heat Tolerance
}

\author{
Amarjeet Kumar*, Swati, Anil Kumar, Sneha Adhikari and Birendra Prasad \\ Department of Genetics and Plant Breeding, College of Agriculture, G. B. Pant University of \\ Agriculture and Technology, Pantnagar-263145, Udham singhnagar, Uttarakhand, India \\ *Corresponding author
}

\begin{tabular}{|l|}
\hline Ke y w o r d s \\
Heat tolerance, \\
Morpho- \\
physiological traits, \\
Variability, Wheat \\
genotypes
\end{tabular}

\section{Introduction}

Wheat, a self-pollinated annual temperate crop plant belongs to the true grass family Gramineae (Poaceae), is the largest cereal crop extensively grown as staple food in the world. The development of an efficient plant hybridization program is dependent upon the

\begin{abstract}
A B S T R A C T
Wheat is self-pollinated annual temperate crop extensively grown as staple food in the world. Thirteen genetically diverse heat tolerance wheat varieties viz.HD3091, DBW90, UP2843, WH1124, HPW211, WH1021, CBW12, MASC6272, JOB666, HD2329, WAXWING, HD2891, HD2961, and three tester HD2967, WH1105, HD3059 was crossed in line $\mathrm{x}$ tester mating design excluding reciprocals. A complete set of 57 genotypes comprised of $39 \mathrm{~F}_{1} \mathrm{~s}$, 13lines and 3 testers along with 2 standard checks (DPW 621-50, UP 2338) were evaluated in the Randomized Block Design (RBD) with three replications during rabi 2014-15. To estimate the level of heat tolerance for different genotypes with respect to morpho-physiological characters like days to $75 \%$ heading, days to maturity, plant height, spike length, peduncle length, awn length, flag leaf area, number of tillers per plant, number of spikelets per spike, 1000-grain weight, biological yield, grain yield per plant, harvest index, number of grains/ spike, grain weight/spike along with grain filling duration, canopy temperature depression (CTD), relative Injury (\%), chlorophyll content and heat susceptibility index (HSI) were recorded. In the present investigation, High heritability associated with high genetic advance reflected for relative injury percent $(0.98$, $43.10 \& 0.99,42.96)$ in both condition, heat susceptibility index $(0.93,0.46)$ and biological yield per plant $(0.89,12.17)$ in timely and late sown condition respectively. For all the morpho-physiological traits studied, the estimates of phenotypic coefficient of variation were exhibited higher than their corresponding genotypic coefficient of variation, indicating that the influence of environment on the expression of these characters was observed.
\end{abstract}

existence of genetic variability (Kumar et al., 2015). The magnitude of genetic variability present in the breeding materials determines the effectiveness of selection. Thus, the success in genetic improvement of any character depends on the nature of variability present in the gene pool for that character. Hence, for a crop species, it is of utmost 
importance to a plant breeder for starting a judicious plant breeding program. Heat stress is defined as the increase in temperature above a critical threshold for a period of time sufficient to cause irreversible damage to plant growth and development (Wahid et al., 2007). The global warming provoked climate change that draw attention of plant breeders to develop wheat genotypes adaptable to adverse abiotic stresses particularly to heat stress during reproductive phase (Kumar et al., 2016). In the Indian subcontinent, the rising temperature coinciding with the reproductive stage is a matter of great concern for wheat breeders. Genetic potential for high yield does exist among the cultivated varieties but biotic and abiotic stress interactions jeopardize the stability of the yield. Therefore, Genetic potential and estimation of diversity and stability performance are measured by some statistical parameters such as mean, variance, coefficient of variation (\%) and genetic gain, heritability (Ali et al., 2008). Grain yield is a complex trait and is greatly influenced by various environmental conditions. Various morpho- physiological traits contribute to grain yield. Each of these component traits has its own genetic systems. Therefore, it is necessary to separate the total variation into heritable and non-heritable components with the help of genetic parameters i.e. genotypic and phenotypic coefficient of variation, heritability and genetic gain (Kahrizi et al., 2010). The phenotypic variance measures the magnitude of variance arising due to genetic component and environmental factors. The heritability is a measure of the genetic relationship between parents and progeny, hence considerable research work has been carried out to incorporate desirable genes in the present wheat varieties to increase the productivity of the crop (Memon et al., 2007).

It is an established fact that greater the variability among the genotypes better is the chance for further improvement in the crop.

\section{Materials and Methods}

The present investigation was carried out at Norman E. Borlaug, Crop Research Centre of Govind Ballabh Pant University of Agriculture and Technology, Pantnagar. India. The material was developed through line $\mathrm{x}$ tester mating during Rabi 2013-14 and their progenies were evaluated in the next Rabi season of 2014-15.Thirteen genetically diverse heat tolerance wheat varieties viz.HD3091, DBW90, UP2843, WH1124, HPW211, WH1021， CBW12， MASC6272， JOB666, HD2329, WAXWING, HD2891, HD2961, and three tester HD2967, WH1105, HD3059 was crossed in line $\mathrm{x}$ tester mating design excluding reciprocals.

A complete set of 57 genotypes comprised of $39 \mathrm{~F}_{1} \mathrm{~s}$, 13lines and 3 testers along with 2 standard checks (DPW 621-50, UP 2338) were evaluated in the Randomized Block Design (RBD) with three replications during rabi 2014-15. Each plot consisted of 2 rows of $1 \mathrm{~m}$ length with a row to row and plant to plant distance of $20 \mathrm{~cm}$ and $10 \mathrm{~cm}$, respectively. To estimate the level of heat tolerance for different genotypes with respect to morphological characters under studied grains/ spike, grain weight/spike, grain filling duration (duration between the anthesis stage and the physiological maturity), 1000-grain weight, grain yield/plant and heat susceptibility index (HSI) for yield which was calculated using the following formula as described by Fischer and Maurer (1978).

$\mathrm{HSI}=(1-\mathrm{Xh} / \mathrm{X}) /(1-\mathrm{Yh} / \mathrm{Y})$

where $\mathrm{Xh}$ and $\mathrm{X}$ are the phenotypic means for each genotype under heat stressed and control conditions, respectively, and $\mathrm{Yh}$ and $\mathrm{Y}$ are the phenotypic means for all genotypes under heat stressed and control conditions, respectively. However, Physiological characters contributing to heat tolerance for various 
genotypes of bread wheat were (i) Canopy temperature depression (CTD) with hand held infrared thermometer, (model AG-42, Tele temp crop, Fullerton CA) was used for instantaneous measurement of canopy minus air temperature as canopy temperature depression at anthesis and 15 days after anthesis at an angle of $30^{\circ}, 50 \mathrm{~cm}$ above the canopy from horizontal and at one meter distance from the edge of the plot end. Data were recorded between 12:00 hrs.to 14:00 hrs. While, (ii) Relative Injury (\%) estimated by following the procedure and formula of Blum and Ebercon (1981): RI $(\%)=\{1-[1-$ (T1/T2)/1-(C1/C2)]\} X 100

Where, $\mathrm{T}$ and $\mathrm{C}$ refer to treatment and control, respectively, and 1 and 2 refer to initial and final conductance readings, respectively. Whereas, (iii) chlorophyll content was recorded in the flag leaves, using a selfcalibrating SPAD chlorophyll meter (Minolta) and data were recorded at anthesis and 15 days after anthesis. Observations were statistically analyzed with the help of Windostat for genetic variability parameter to determine allelic diversity.

\section{Results and Discussion}

In the present investigation result of analyzed data revealed that a wide range of allelic variability exhibited for the trait under studied (Table 1). The highest value (0.98) for heritability was observed by relative injury percent followed by heat susceptibility index (0.93) and lowest value was observed for days to maturity $(0.14)$ followed by grains weight per spike (0.15) in timely sown condition. Whereas, relative injury percent (0.99) followed by canopy temperature depression 15 days after anthesis (0.91) were the two most heritable traits and chlorophyll content at anthesis (0.12) and days to maturity (0.18) were least heritable traits in late sown condition.
A perusal of genetic advance revealed that it was high for relative injury percent (43.10), biological yield per plant (35.68) and moderate estimates were exhibited by flag leaf area (8.05), grain yield per plant (8.77), tillers per plant (6.11) and low genetic advance was observed for grain weight per spike (0.16), heat susceptibility index(0.46), awn length (0.49), canopy temperature depression (0.52), days to maturity $(0.78)$, spikelets per spike $(0.87)$ in timely sown condition.

However, in late sown condition genetic advance was reflected high for relative injury percent (42.96), biological yield per plant (12.17), harvest index (10.23) and the moderate value were observed by flag leaf area (5.94), 1000 kernel weight (4.95), grains per spike (3.62) along with low value were estimated for grain weight per spike (0.21), spike length (0.50), days to maturity (0.79) awn length (0.86).

High heritability associated with high genetic advance reflected for relative injury percent $(0.98,43.10 \& 0.99,42.96)$ in both condition, heat susceptibility index $(0.93,0.46)$ and biological yield per plant $(0.89,12.17)$ in timely and late sown condition respectively. High heritability and high genetic advance indicates that preponderance of additive gene effect (Panse, 1967) therefore, characters can be better exploited through selection.

High heritability associated with low genetic advance was exhibited by canopy temperature depression $(0.71,1.64)$ and canopy temperature depression 15 days after anthesis $(0.91,1.72)$ in timely and late sown condition respectively. This may be because of predominance of non - additive gene action in the expression of these traits. The high heritability of these characters was due to favorable influence of environment rather than genotypic and selection for these traits may not be rewarding. 
Table.1 Heritability, Genetic Advance (GA), Genotypic Coefficient of Variation (GCV), Phenotypic Coefficient of Variation (PCV) of wheat genotypes for different morphophysiological traits (Timely and late sown environments)

\begin{tabular}{|c|c|c|c|c|c|c|c|c|c|c|c|}
\hline & \multirow[t]{3}{*}{ Character } & \multirow{2}{*}{\multicolumn{5}{|c|}{ Timely Sown Condition (E1) }} & & & & & \\
\hline & & & & & & & \multicolumn{5}{|c|}{ Late Sown Condition (E2) } \\
\hline & & $\mathbf{H}^{2}$ & GA & $\begin{array}{l}\text { GCV } \\
(\%)\end{array}$ & $\begin{array}{l}\text { PCV } \\
(\%)\end{array}$ & $\begin{array}{c}\text { ECV } \\
(\%)\end{array}$ & $\mathbf{H}^{2}$ & GA & $\begin{array}{c}\text { GCV } \\
(\%)\end{array}$ & $\begin{array}{c}\text { PCV } \\
(\%)\end{array}$ & $\begin{array}{r}\text { ECV } \\
(\%)\end{array}$ \\
\hline 1 & Days to $75 \%$ heading & 0.67 & 3.35 & 2.27 & 2.77 & 1.60 & 0.51 & 2.01 & 1.82 & 2.55 & 1.78 \\
\hline 2 & Days to maturity & 0.14 & 0.78 & 0.79 & 2.10 & 1.94 & 0.18 & 0.79 & 0.83 & 1.99 & 1.80 \\
\hline 3 & plant height $(\mathrm{cm})$ & 0.22 & 2.57 & 2.73 & 5.80 & 5.12 & 0.27 & 3.08 & 3.56 & 6.90 & 5.91 \\
\hline 4 & Spike length $(\mathrm{cm})$ & 0.42 & 1.05 & 6.42 & 9.89 & 7.52 & 0.20 & 0.50 & 5.48 & 12.22 & 10.92 \\
\hline 5 & Peduncle length $(\mathrm{cm})$ & 0.47 & 2.74 & 5.70 & 8.35 & 6.10 & 0.58 & 3.24 & 6.43 & 8.47 & 5.51 \\
\hline 6 & Awn length $(\mathrm{cm})$ & 0.30 & 0.49 & 7.99 & 14.57 & 12.19 & 0.5 & 0.86 & 9.42 & 13.36 & 9.47 \\
\hline 7 & Tillers/ plant & 0.81 & 6.11 & 23.66 & 26.21 & 11.28 & 0.67 & 3.10 & 16.52 & 20.25 & 11.71 \\
\hline 8 & Spikelets/ spike & 0.34 & .0 .87 & 3.74 & 6.47 & 5.27 & 0.38 & 1.22 & 5.41 & 8.74 & 6.86 \\
\hline 9 & Flag leaf area $\left(\mathrm{cm}^{2}\right)$ & 0.73 & 8.05 & 15.49 & 18.13 & 9.41 & 0.78 & 5.94 & 18.52 & 21.01 & 9.92 \\
\hline 10 & 1000 grain weight & 0.54 & 4.72 & 7.38 & 10.01 & 6.76 & 0.49 & 4.95 & 11.69 & 16.76 & 12.00 \\
\hline 11 & Grain weight/ spike & 0.15 & 0.16 & 6.60 & 17.09 & 15.76 & 0.30 & 0.21 & 11.36 & 20.66 & 17.26 \\
\hline 12 & Grain yield/ plant & 0.88 & 8.77 & 20.96 & 22.40 & 7.89 & 0.74 & 3.30 & 22.18 & 25.88 & 13.19 \\
\hline 13 & Biological yield/ plant & 0.72 & 35.68 & 23.79 & 28.14 & 15.02 & 0.89 & 12.17 & 22.13 & 23.40 & 7.60 \\
\hline 14 & Harvest index & 0.29 & 2.05 & 5.04 & 9.29 & 7.81 & 0.73 & 10.23 & 18.67 & 21.91 & 11.46 \\
\hline 15 & Grains/ spike & 0.25 & 2.29 & 3.94 & 7.89 & 6.84 & 0.38 & 3.62 & 5.60 & 9.06 & 7.13 \\
\hline 16 & Relative injury (\%) & 0.98 & 43.10 & 47.69 & 48.14 & 6.56 & 0.99 & 42.96 & 43.38 & 43.69 & 5.17 \\
\hline 17 & $\begin{array}{l}\text { Chlorophyll content at } \\
\text { anthesis }\end{array}$ & 0.26 & 1.71 & 3.36 & 6.59 & 5.67 & 0.12 & 1.00 & 2.97 & 8.66 & 8.14 \\
\hline 18 & $\begin{array}{l}\text { Chlorophyll content At } \\
\text { 15DAA }\end{array}$ & 0.44 & 3.05 & 4.79 & 7.25 & 5.44 & 0.20 & 2.42 & 6.06 & 13.42 & 11.97 \\
\hline 19 & CTD at anthesis & 0.71 & 1.64 & 20.58 & 24.48 & 13.25 & 0.88 & 1.49 & 35.80 & 38.06 & 12.91 \\
\hline 20 & CTD at $15 \mathrm{DAA}$ & 0.36 & 0.52 & 12.06 & 20.02 & 15.98 & 0.91 & 1.72 & 39.73 & 41.74 & 12.80 \\
\hline 21 & Grain filling duration & 0.27 & 1.79 & 4.75 & 9.09 & 7.75 & 0.25 & 0.86 & 2.88 & 5.77 & 5.00 \\
\hline 22 & Heat susceptibility index & 0.93 & 0.46 & 25.12 & 26.09 & 7.06 & & & & & \\
\hline
\end{tabular}

DAA = Days after anthesis, CTD = Canopy temperature depression

The present findings is in close confirmation with the findings of (Kumar et al., 2014;) estimated the genotypic coefficient of variation $(\mathrm{GCV})$ and phenotypic coefficient of variation $(\mathrm{PCV})$ revealed that phenotypic coefficient of variation were higher than genotypic coefficient of variation, which indicates less effect of environment on the expression of characters studied. Highest estimates of GCV and PCV were observed for grain yield per plant followed by biological yield and harvest index (GCV 22.87 and PCV 23.03).
The highest variability (PCV and GCV) was recorded for relative injury percent (47.69, 48.14 \& 43.38, 43.69) in both condition followed by biological yield per plant (23.79, $28.14)$ and grain yield per plant $(22.18,25.88)$ in timely and late sown condition respectively. Whereas, the low values were observed for $75 \%$ days to heading $(2.27,2.77)$ and days to maturity $(0.83,1.99)$ in timely and late sown condition respectively. In the present investigation, for all the morphophysiological traits studied, the estimates of phenotypic coefficient of variation were 
exhibited higher than their corresponding genotypic coefficient of variation, indicating that the influence of environment on the expression of these characters was observed.

Also it can be interpreted as less difference in the estimates of genotypic and phenotypic variance reflected little influence of environment on these traits and higher genotypic values compared to environmental variances for all the characters suggested that the variability present among the genotypes were mainly due to genetic reason with minimum influence of environment and hence heritable.

The results are parity with the findings of (Saleem et al., 2006; Rahman et al., 2016) observed that these characters had also medium to high genotypic coefficient of variation and phenotypic coefficient of variation coupled with high to moderate heritability and genetic advance.

In the present investigation, High heritability associated with high genetic advance reflected for relative injury percent $(0.98,43.10 \&$ $0.99,42.96)$ in both condition, heat susceptibility index $(0.93,0.46)$ and biological yield per plant $(0.89,12.17)$ in timely and late sown condition respectively.

All the morpho-physiological traits studied, the estimates of phenotypic coefficient of variation were exhibited higher than their corresponding genotypic coefficient of variation, it can be interpreted as less difference in the estimates of genotypic and phenotypic variance reflected little influence of environment on these traits and higher genotypic values compared to environmental variances for all the characters suggested that the variability present among the genotypes were mainly due to genetic reason with minimum influence of environment and hence heritable.

\section{References}

Ali, Y., Atta, B. M., Akhter, J., Monneveux, P., Lateef, Z. 2008. Genetic variability, association and diversity studies in wheat (Triticum aestivum L.) germplasm. Pak. J. Bot., 40: 20872097.

Blum, A. and Ebercon, A. 1981. Cell membrane stability as a measure of drought and heat tolerance in wheat. Crop Sci. J., 21: 43-47.

Fischer, R. A. and Maurer, R. 1978. Drought resistance in spring wheat cultivars: 1 . Grain-yield responses. Aust. J. Agric. Res., 29: 897-912.

Kahrizi, D., Cheghamriza, K., Kakaei, M., Mohammadi, R., Ebadi, A. 2010. Heritability and genetic gain of some morpho-physiological variables of durum wheat (Triticum turgidumvar. durum). Afr. J. Biotechnol., 9(30): 4687 $-4691$.

Kumar, A. Swati, Jaiswal, J. P., Prasad, B., Bharati, A. and Goel, P. 2016. Characterization of Wheat Genotypes Using Morpho- Physiological Traits for Heat Tolerance. Appl. Biol. Res., 18(2):8-15.

Kumar, A., Harshwardhan, Kumar, A. and Prasad, B. 2015. Combining ability and gene interaction study for yield, its attributing traits and quality in common wheat. J. Appl. \& Nat. Sci., 7 (2): 927 934.

Kumar, N., Markar, S. and Kumar, V. 2014. Studies on heritability and genetic advance estimates in timely sown bread wheat (Triticum aestivum L.). Bioscience Discovery, 5(1): 64-69.

Memon, S.M., Qureshi, M.U., Ansari, B.A. and Sial, M.A. 2007. Genetic heritability for grain yield and its related characters in spring wheat. Pak. J. Bot. 39 (5):1503- 1509.

Rahman, M. A., Kabir, M. L., Hasanuzzaman, 
M., Rahman, M. A., Rumi, R. H., Afrose, M. T. 2016. Study of variability in bread wheat (Triticum aestivum L.). International Journal of Agronomy and Agricultural Research (IJAAR), 8(5):66-76.

Saleem, U., Khaliq, I., Mahmood, T. and Rafique, M. 2006. Phenotypic and genotypic correlation coefficient between yield and yield components in wheat. J. Agric. Res., 44(1):1 -6.

Wahid, A., Gelani, S., Ashraf, M. and Foolad, M. R. 2007. Heat tolerance in plants: An overview. Environmental and Experimental Botany, 61:199-223.

\section{How to cite this article:}

Amarjeet Kumar, Swati, Anil Kumar, Sneha Adhikari and Birendra Prasad. 2018. Genetic Dissection of Wheat Genotypes Using Morpho-Physiological Traits for Terminal Heat Tolerance. Int.J.Curr.Microbiol.App.Sci. 7(02): 367-372. doi: https://doi.org/10.20546/ijcmas.2018.702.048 